\title{
Is every patient eligible to have an office hysteroscopy? A retrospective analysis of 1301 procedures
}

\author{
Magdalena M. Biela, Jacek Doniec, Monika Szafarowska, Kamil Sobocinski, Andrzej Kwiatkowski, Paweł Kamiński \\ Department of Gynecology and Oncological Gynecology, Military Institute of Medicine, Warsaw, Poland
}

Videosurgery Miniinv 2020; 15 (2): 337-345

DOI: https://doi.org/10.5114/wiitm.2019.89609

\begin{abstract}
Introduction: Hysteroscopy is the gold standard for diagnosis and treatment of uterine pathologies. The office setting seems to be safe, reducing the anesthesia risks and also decreasing the overall costs of the procedure. Recent literature suggests that hysteroscopy performed without anesthesia may not be as painless as it was previously considered. Moreover, not every patient can be referred for a hysteroscopy in an office setting.

Aim: To analyze the factors correlated with a successful hysteroscopy in an office setting.

Material and methods: We analyzed the documentation of 1301 patients who underwent hysteroscopy at our department in the period 2013-2016. The impact of the type of the procedure and the various demographic factors on the need for general anesthesia was assessed.

Results: Almost $80 \%$ of all hysteroscopies were performed without analgesia in an office setting. The remaining patients underwent a hysteroscopy in general anesthesia. The key aspect for successful office hysteroscopy is the scope of the performed surgery. Over $91 \%$ of diagnostic hysteroscopies have been done without analgesia, but only about $30 \%$ of extensive endometrial scratching procedures were performed in an office setting. A previous vaginal delivery increases the chances for a successful office hysteroscopy by about $21 \%$, and in the case of diagnostic procedures, multiparous patients were at an about $79 \%$ lower risk of analgesia necessity.

Conclusions: It is possible to perform nearly all diagnostic hysteroscopies in an office setting. In the case of operative hysteroscopy, the most crucial factor is the scope of the procedure.
\end{abstract}

Key words: hysteroscopy, pain, vaginoscopy, anesthesia, office hysteroscopy.

\section{Introduction}

Hysteroscopy is a gold standard for diagnosing and treatment intrauterine pathologies [1, 2]. Over the years, hysteroscopic equipment has changed, and so have the procedure settings. Initially, hysteroscopy was performed in the operative room $(\mathrm{OR})$, mostly in general anesthesia. Since that time, several different techniques of analgesia have been tested, including local anesthesia, oral or vaginal premedication or intrauterine analgesia [3-5]. The greatest breakthrough was the moment of introduc- ing an office setting for hysteroscopy where no anesthesia nor analgesia was used. It was possible mainly thanks to minimization of the equipment and the introduction of the new, 'no-touch' technique called vaginoscopy [6]. In several prospective randomized trials it was proved that the transvaginal approach is better tolerated than the conventional technique in outpatient hysteroscopy [7-9]. The office setting seems to be safe, reducing the risks of anesthesia and also decreasing the overall costs of the procedure [10]. Despite the fact that the advantages of office hysteroscopy were described more than 
10 years ago, in certain countries the outpatient setting is still not popular, and nearly all hysteroscopies are performed in general anesthesia.

\section{Aim}

This study presents a single center's experience in hysteroscopy procedures performed in an office setting. We have analyzed the rate of the hysteroscopic procedures performed without analgesia and anesthesia, and various factors that may be responsible for a failure of office hysteroscopy. The main aim was to find the most significant predictive factors of successful office hysteroscopy.

\section{Material and methods}

This manuscript presents a retrospective analysis of 1301 hysteroscopies performed at the Department of Gynecology and Oncologic Gynecology, Military Institute of Medicine, Warsaw, Poland, in the period 2013-2016. The study was approved by the local ethical committee: 4/WIM/2016 (20.01.2016) and there was no form of conflict of interest.

We analyzed the documentation of all hysteroscopies carried out at our department in the period 2013-2016. All procedures performed using the standard $9 \mathrm{~mm}$ resectoscope were excluded from the analysis.

We assessed the impact of the type of the procedure performed in hysteroscopy and various demographic factors, such as age, parity, menopausal status, and the need for general anesthesia for hysteroscopy.

All patients were women aged over 18, with a confirmed indication for a diagnostic or operative hysteroscopy. The main indications for the proce-

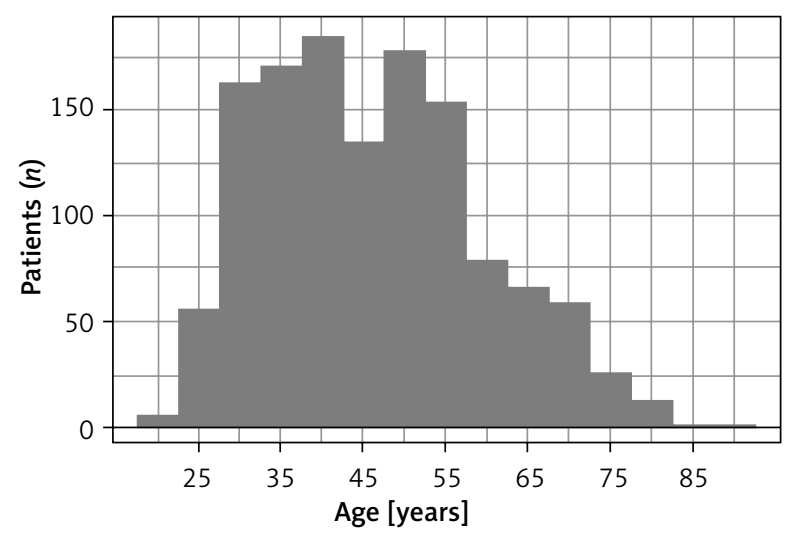

Figure 1. Age distribution of patients dure were: endometrial polyps, infertility, abnormal uterine bleeding, submucosal myomas and uterine septum. Patients with large myomas $(>2 \mathrm{~cm}$ ) or very large endometrial polyps $(>3 \mathrm{~cm}$ ) were usually offered a hysteroscopy in general anesthesia directly. All patients had signed a written informed consent form before the procedure. The patients' age distribution is shown in Figure 1.

The exclusion criteria for hysteroscopy were: the presence of heavy uterine bleeding, suspected pregnancy, suspected pelvic inflammatory disease and ongoing vaginal infections.

\section{The procedure}

In the premenopausal group, all procedures were performed in the proliferative phase of the menstrual cycle. In the postmenopausal patients, there were no restrictions regarding the day of the procedure. No hormonal preparation was applied as a standard.

All office procedures were performed with aseptic rules, in the same setting: the patient in a gynecologic position, no analgesia or anesthesia, no disinfection of the vagina. No hysteroscopies in local anesthesia (such as intracervical blocks, paracervical blocks or intrauterine anesthesia) were performed at our department. The vaginoscopic approach was used in all patients (no use of a vaginal speculum or a tenaculum). The use of misoprostol for cervix preparation before the hysteroscopy was avoided. No premedication or antibiotic prophylactic was used before the procedure.

The hysteroscopy was performed using the rigid $5 \mathrm{~mm}$ or $4.2 \mathrm{~mm}$ continuous flow operative Bettocchi hysteroscope (Karl Storz, Germany) with a 30* fore-oblique lens.

The vaginoscopic approach was performed as previously described [11]. The hysteroscope was placed into the vagina, which was filled with normal saline. After identifying the cervix and the external ostium, the instrument was introduced into the cervical canal and guided into the uterine cavity. The cervical canal and the uterine cavity were inspected systematically. The uterine cavity was distended with a normal saline solution at a pressure below 60 $\mathrm{mm} \mathrm{Hg}$, controlled by an electronic irrigation pump (Endomat, Karl-Storz, Germany). For the operative procedures, the following semirigid $5 \mathrm{Fr}$ instruments were used: scissors, a grasper, a tenaculum, and the bipolar Twizzle Tip Versapoint electrode (Gynecare, 


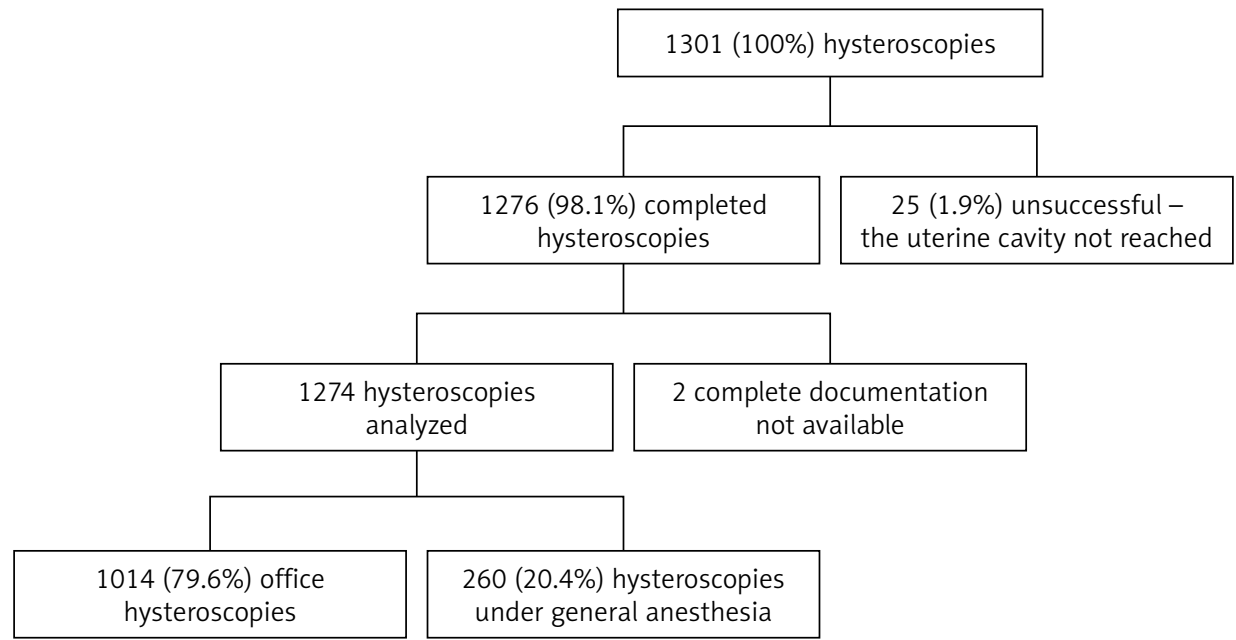

Figure 2. Analysis of hysteroscopies performed at the Gynecology and Oncological Gynecology Clinic, Military Institute of Medicine, Warsaw in 2013-2016

Ethicon). All procedures were performed by surgeons experienced in hysteroscopy.

During the office hysteroscopy the patient had continuous contact with the surgeon and could report the discomfort and pain intensity at any time during the procedure. In every situation when the pain was intolerable for the patient, the office procedure was stopped and continued later in general anesthesia in the operative room.

After the surgery, the patients were observed for at least $1 \mathrm{~h}$ for any adverse event occurrence, and then discharged home.

Only completed procedures performed without any form of analgesia or anesthesia were considered as office hysteroscopies eligible for our study.

\section{Statistical analysis}

Statistical analyses were performed using the $R$ 3.1.2 statistical software pack (R Core Team; 2014. R: A language and environment for statistical computing. R Foundation for Statistical Computing, Vienna, Austria. URL http://www.R-project.org/). The $p$-value $<0.05$ was considered statistically significant. In descriptive statistics, the categorical variables are presented as the quantity and percentage of occurrences. In order to identify the impact of the investigated parameters on the possibility of performing a hysteroscopy procedure without analgesia, single-factor logistic regression analysis was used. The results reported the odds ratio (OR) with a $95 \%$ confidence interval $(\mathrm{Cl})$ and the Wald test $p$-value. The results are presented in the tables and figures.

\section{Results}

In the period 2013-2016, a total of 1301 hysteroscopic procedures were performed at our department. In 25 (1.9\%) cases, the uterine cavity was not reached. Among the other 1276 patients, in 2 cases information about the exact type of the performed procedure was not available. The remaining 1274 successful procedures with their complete medical histories were analyzed further (Figure 2).

Out of all hysteroscopic procedures, an endometrial polyp resection was the most commonly performed, and accounted for about $50 \%$ of all the interventions. The exact distribution of all hysteroscopic procedures depending on the surgery type is shown in Figure 3.

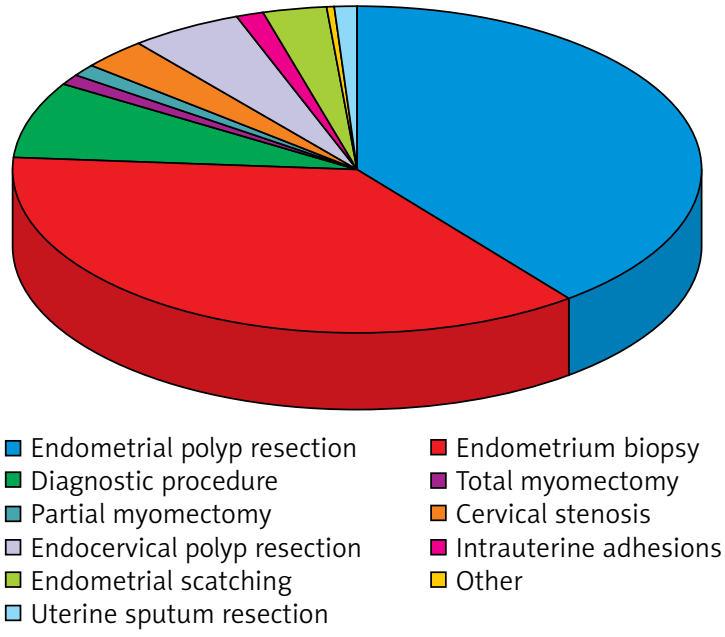

Figure 3. Distribution of all hysteroscopic procedures depending on surgery type 
Table I. Percentage of hysteroscopic procedures performed with and without anesthesia (more than one procedure possible for 1 patient)

\begin{tabular}{|lcc|}
\hline Hysteroscopic procedure & $\begin{array}{c}\text { Office setting - no anesthesia } \\
n(\%)\end{array}$ & $\begin{array}{c}\text { General anesthesia } \\
n(\%)\end{array}$ \\
\hline Total hysteroscopies & $1014(79.6)$ & $260(20.4)$ \\
\hline Endometrial polyp resection & $485(76.3)$ & $150(23.7)$ \\
\hline Endometrium biopsy & $431(83.7)$ & $84(16.3)$ \\
\hline Diagnostic procedure & $109(90.8)$ & $11(9.2)$ \\
\hline Total myomectomy & $12(63.2)$ & $7(36.8)$ \\
\hline Partial myomectomy & $11(61.1)$ & $7(38.9)$ \\
\hline Cervical stenosis & $47(85.5)$ & $8(24.5)$ \\
\hline Endocervical polyp resection & $78(85.7)$ & $13(24.3)$ \\
\hline Intrauterine adhesions & $17(68.0)$ & $37(69.8)$ \\
\hline $\begin{array}{l}\text { Endometrial scratching (large endometrial } \\
\text { biopsy, partial endometrium resection) }\end{array}$ & $16(30.2)$ & $1(16.7)$ \\
\hline Other & $5(83.3)$ & $5(26.3)$ \\
\hline Uterine septum resection & $14(73.7)$ & \\
\hline
\end{tabular}

The total number of hysteroscopies performed without analgesia in an office setting was 1014 (79.6\%). The other cases were carried out in general anesthesia due to a presurgery qualification (very large myomas or endometrial polyps) or due to intolerable pain during the office procedure (of-

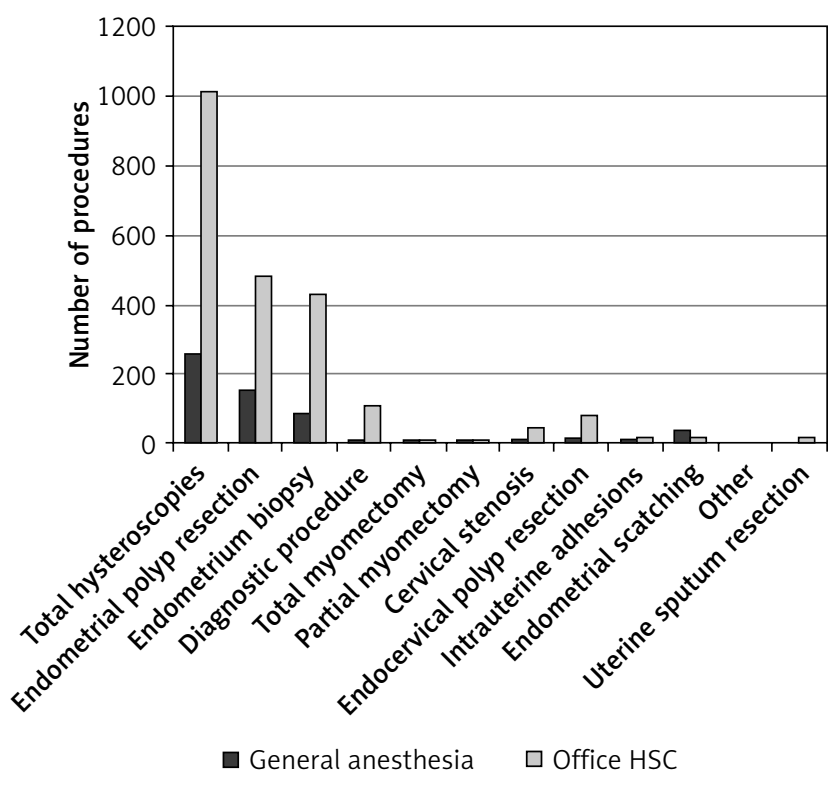

Figure 4. Distribution of hysteroscopies performed with and without anesthesia depending on type of procedure fice hysteroscopy failure). The exact number of procedures performed without anesthesia is presented in Table I.

Almost $91 \%$ of all diagnostic hysteroscopies where no biopsy for a histologic examination was taken were conducted in an office setting (without anesthesia). In comparison, only $30 \%$ of endometrial scratching procedures, where a large volume of the endometrial tissue was extracted from the uterus, were performed in the same setting, while the remaining $70 \%$ of patients required general anesthesia for this kind of treatment. Also, partial and total myomectomy required general anesthesia in more than $1 / 3$ cases $(38.9 \%$ and $36.8 \%$, accordingly) (Figure 4).

No statistically significant differences in the percentage of office procedures were found between the pre-menopausal and post-menopausal patients $(79 \%$ vs. $81.9 \%, p=0.276)$. For nearly all kinds of interventions, except the endometrial biopsy, a higher percentage of procedures without anesthesia was performed in the postmenopausal group, but the difference was statistically significant only for cervical stenosis dilatation $(p=0.042)$ (Table II, Figure 5).

Additionally, the patient's age was not a statistically significant factor for carrying out a hys- 
Table II. Number of hysteroscopies performed without anesthesia depending on the menopausal status of the patient (more than one procedure possible for 1 patient)

\begin{tabular}{|c|c|c|c|c|}
\hline Hysteroscopic procedure & Total, $n(\%)$ & $\begin{array}{l}\text { Pre-menopausal } \\
\text { women, } n(\%)\end{array}$ & $\begin{array}{l}\text { Post-menopausal } \\
\text { women, } n(\%)\end{array}$ & $P$-value \\
\hline Total hysteroscopies & $1014(79.6)$ & $670(79.0)$ & $312(81.9)$ & 0.276 \\
\hline Endometrial polyp resection & $485(76.3)$ & $298(74.7)$ & $173(79.0)$ & 0.269 \\
\hline Endometrium biopsy & $431(83.7)$ & $326(85.1)$ & $96(80.0)$ & 0.235 \\
\hline Diagnostic procedure & $109(90.8)$ & $71(91.0)$ & $34(97.1)$ & 0.431 \\
\hline Total myomectomy & $12(63.2)$ & $9(56.2)$ & $3(100.0)$ & 0.263 \\
\hline Partial myomectomy & $11(61.1)$ & $5(62.5)$ & $5(62.5)$ & 1.000 \\
\hline Cervical stenosis & $47(85.5)$ & $14(70.0)$ & 31 (93.9) & 0.042 \\
\hline Endocervical polyp resection & $78(85.7)$ & $45(81.8)$ & $31(91.2)$ & 0.355 \\
\hline Intrauterine adhesions & $17(68.0)$ & $11(64.7)$ & $5(83.3)$ & 0.621 \\
\hline $\begin{array}{l}\text { Endometrial scratching (large } \\
\text { endometrial biopsy, partial } \\
\text { endometrium resection) }\end{array}$ & $16(30.2)$ & $8(22.9)$ & $6(40.0)$ & 0.304 \\
\hline Other & $5(83.3)$ & $3(75.0)$ & $2(100.0)$ & 1.000 \\
\hline Uterine septum resection & $14(73.7)$ & $12(75.0)$ & $\mathrm{O}(\mathrm{NaN})$ & NA \\
\hline
\end{tabular}

teroscopy without anesthesia. The percentages of successful office hysteroscopies were similar in all age groups. A statistically significant difference was found only for total and partial myomectomies and cervical canal polyp resections. In the global view, the chances for a successful hysteroscopy without analgesia increase with the age of the patient. Nevertheless, the observed trend may result from the parity status of the women (older women are more likely to be multiparous) (Table III).

In our analysis, the multiparous status of the woman is one of the most prominent predictive factors for successful office hysteroscopy, irrespectively of the indications. In a detailed analysis, a statistically significant difference was observed for endometrial and cervical polyp resections, as well as for diagnostic hysteroscopies. In the case of diagnostic procedures, almost all of them were performed without anesthesia (97\%) (Figure 6, Table IV).

In the logistic regression model, the chances for a successful diagnostic hysteroscopy in an office setting rise about $79 \%$ for every woman who has delivered a child vaginally (in comparison to nulliparous). For all other kinds of hysteroscopic procedures, the parity status is also important, but vaginal delivery increases the chance for a successful procedure without anesthesia by about $21 \%$.

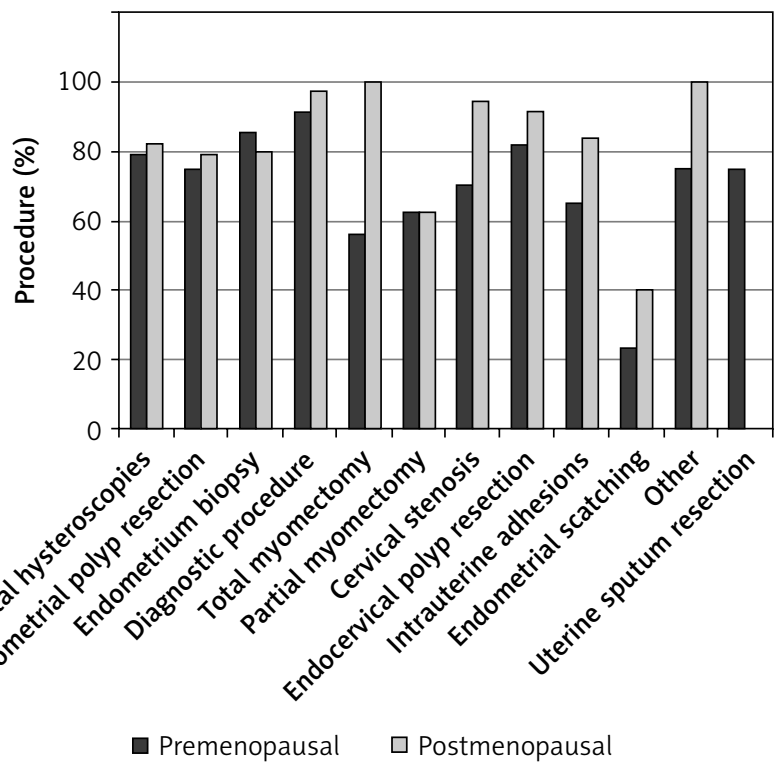

Figure 5. Percentages of hysteroscopies performed in office setting depending on the menopausal status of the patient

\section{Discussion}

At our department, almost $80 \%$ of all hysteroscopic procedures in the period 2013-2016 were performed in an office setting without analgesia or anesthesia. This is mainly a result of using the vag- 
Table III. Number and percentage of office hysteroscopies (without anesthesia) in the different age groups (more than one procedure possible for 1 patient)

\begin{tabular}{|c|c|c|c|c|c|c|}
\hline Hysteroscopic procedure & $\begin{array}{c}\text { Total } \\
(1274=100 \%) \\
n(\%)\end{array}$ & $\begin{array}{c}\text { Age } \leq 35 \\
n(\%)\end{array}$ & $\begin{array}{c}\text { Age } 36-45 \\
n(\%)\end{array}$ & $\begin{array}{c}\text { Age } 46-55 \\
n(\%)\end{array}$ & $\begin{array}{c}\text { Age }>55 \\
n(\%)\end{array}$ & $P$-value \\
\hline Total office minihysteroscopies & $1014(79.6)$ & $247(77.2)$ & $258(79.1)$ & $260(79.3)$ & $243(83.2)$ & 0.312 \\
\hline Endometrial polyp resection & $485(76.3)$ & $100(73.5)$ & $120(75.9)$ & $121(76.1)$ & $143(78.6)$ & 0.776 \\
\hline Endometrium biopsy & $431(83.7)$ & $91(83.5)$ & $139(81.8)$ & $131(84.0)$ & $66(88.0)$ & 0.683 \\
\hline Diagnostic procedure & $109(90.8)$ & $46(85.2)$ & $19(95.0)$ & $20(100.0)$ & $23(95.8)$ & 0.174 \\
\hline Total myomectomy & $12(63.2)$ & $0(0.0)$ & $2(100.0)$ & $7(70.0)$ & $3(100)$ & 0.016 \\
\hline Partial myomectomy & $11(61.1)$ & $4(100.0)$ & $0(0.0)$ & $4(80.0)$ & $3(60.0)$ & 0.027 \\
\hline Cervical stenosis & $47(85.5)$ & $7(77.8)$ & $4(66.7)$ & $8(80.0)$ & $28(93.3)$ & 0.139 \\
\hline Endocervical polyp resection & $78(85.7)$ & $13(76.5)$ & $15(83.3)$ & $24(80.0)$ & $26(100)$ & 0.037 \\
\hline Intrauterine adhesions & $17(68.0)$ & $8(72.7)$ & $4(50.0)$ & $1(100.0)$ & $3(75.0)$ & 0.678 \\
\hline $\begin{array}{l}\text { Endometrial scratching (large } \\
\text { endometrial biopsy, partial } \\
\text { endometrium resection) }\end{array}$ & $16(30.2)$ & $0(0.0)$ & $6(37.5)$ & $7(30.4)$ & $3(27.3)$ & 0.777 \\
\hline Other & $5(83.3)$ & $2(100.0)$ & $1(50.0)$ & $0(\mathrm{NaN})$ & $2(100)$ & 1.000 \\
\hline Uterine septum resection & $14(73.7)$ & $11(68.8)$ & $3(100.0)$ & $0(\mathrm{NaN})$ & $0(\mathrm{NaN})$ & 0.530 \\
\hline
\end{tabular}
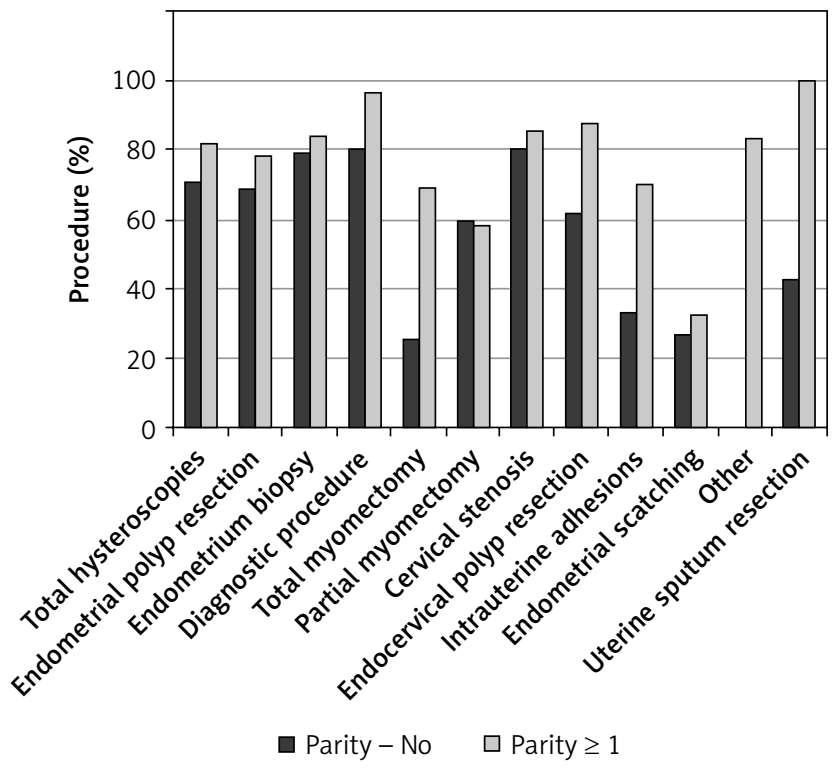

Figure 6. Percentages of office hysteroscopies in nulliparous and multiparous population

inoscopic approach, which is a standard practice at the department. It has been proved that the vaginoscopic, 'no touch' technique for outpatient hysteroscopy is successful and significantly reduces the pain experienced by patients during the procedure, as compared to the techniques using a vaginal speculum [12].

Considering only the diagnostic procedures, the percentage of successful office procedures rises to about $91 \%$. These results are comparable to those reported in the literature $[1,13]$. As it was supposed, diagnostic hysteroscopy seems to be the best tolerated of all hysteroscopic procedures, and less than $10 \%$ of patients require general anesthesia for this kind of intervention. Despite the fact that in our trial, as well as in other ones, the vast majority of the hysteroscopies were carried out successfully without analgesia, scientists started to consider if office hysteroscopy is really painless. Certain authors believe that it might be objectively more painful than it was previously supposed. A recent systematic review and meta-analysis showed that about $31 \%$ of women undergoing hysteroscopy refer to a tolerable discomfort [14]. This is the reason why other, less painful diagnostic procedures are recently being compared to hysteroscopy. A randomized comparison of vaginoscopic office hysteroscopy and saline infusion sonography (SIS) proved that SIS causes significantly less discomfort than office hysteroscopy [15]. Considering the fact that the diagnostic accuracy of saline infusion sonography 
Table IV. Number and percentage of office hysteroscopies (without anesthesia) in nulliparous and multiparous population

\begin{tabular}{|lcccc|}
\hline Hysteroscopic procedure & $\begin{array}{c}\text { Total (\%) } \\
n(\%)\end{array}$ & $\begin{array}{c}\text { Parity - No } \\
n(\%)\end{array}$ & $\begin{array}{c}\text { Parity } \geq 1 \\
n(\%)\end{array}$ & $P$-value \\
\hline Total hysteroscopies & $1014(79.6)$ & $208(70.7)$ & $731(81.9)$ & $<0.001$ \\
\hline Endometrial polyp resection & $485(76.3)$ & $109(69.0)$ & $344(78.5)$ & 0.021 \\
\hline Endometrium biopsy & $431(83.7)$ & $76(79.2)$ & $332(84.3)$ & 0.295 \\
\hline Diagnostic procedure & $109(90.8)$ & $33(80.5)$ & $65(97.0)$ & 0.006 \\
\hline Total myomectomy & $12(63.2)$ & $1(25.0)$ & $9(69.2)$ & 0.250 \\
\hline Partial myomectomy & $11(61.1)$ & $3(60.0)$ & $7(58.3)$ & 1.000 \\
\hline Cervical stenosis & $47(85.5)$ & $4(80.0)$ & $42(85.7)$ & 0.567 \\
\hline Endocervical polyp resection & $78(85.7)$ & $8(61.5)$ & $58(87.9)$ & 0.034 \\
\hline Intrauterine adhesions & $17(68.0)$ & $1(33.3)$ & $14(70.0)$ & 0.269 \\
\hline Endometrial scratching & $16(30.2)$ & $4(26.7)$ & $12(32.4)$ & 0.752 \\
\hline Other & $5(83.3)$ & $0(\mathrm{NaN})$ & $5(83.3)$ & NA \\
\hline Uterine septum resection & $14(73.7)$ & $3(42.9)$ & $4(100.0)$ & 0.194 \\
\hline
\end{tabular}

(SIS) equals the accuracy of diagnostic hysteroscopy [16], the authors of the comparison concluded that SIS should be considered the method of choice in diagnostic procedures [15]. We do agree that SIS may be useful in certain cases, especially for diagnosing and planning the treatment of such intrauterine pathologies as endometrial polyps, submucosal myoma and uterine septum. Nevertheless, this method is not comparable to hysteroscopy, which enables the pathology to be diagnosed and treated immediately at the same time ('see and treat').

In our analysis, the failure rate of all hysteroscopies is less than $2 \%$, which is lower than the $10 \%$ published in the previous literature [17]. The reason for such a good result may be the fact that all procedures included in our analysis were conducted by gynecologists who are very experienced in hysteroscopy.

The parity status of the patient was the most important predictive factor of successful office hysteroscopy in our study. Campo et al. over 10 years ago presented similar results of a randomized prospective trial. They also suggest that procedures performed by experienced surgeons are less painful [18]. This factor was not analyzed in our study due to the fact that all of the hysteroscopies were performed by a small group of experienced gynecologists.

The menopausal status of the patient does not seem to influence the total probability of anesthe- sia for hysteroscopy. This conclusion is consistent with the literature, where the menopausal status does not influence the level of pain during hysteroscopy [19]. However, in our study, the percentage of the procedures performed without anesthesia was slightly higher in postmenopausal women, and in the case of cervical dilatation, the difference was statistically significant. This finding is in contradiction with other studies. Gambadauro et al. found an independent association of a successful see-andtreat hysteroscopic polypectomy with the premenopausal status [20].

In our practice, we do not use any kind of hormonal treatment before the hysteroscopy. However, in the literature there are certain data on the hormonal preparation of the endometrium. Preoperative administration of dienogest may reduce the endometrial thickness, and at the same time facilitate visualization of the uterine cavity and reduce the duration of the surgery [21]. Therefore, performing hysteroscopy in the proliferation phase, before the $12-14^{\text {th }}$ day of the cycle, in our opinion is a sufficient factor for a successful office hysteroscopy.

An interesting finding of our study is that in postmenopausal women most of the cervical canal dilatations were done without anesthesia, and the difference was statistically significant. The possible reason for this result may be lower sensitivity of the 
cervix in women after their last period. However, further research is needed to confirm this statement.

In recent years, the range of hysteroscopic tools has expanded and new instruments have appeared. They include the hysteroscopic tissue removal systems (HTRs), which were not used in this trial, because they were was not available at the department. The HTRs are a good and safe option for the management of intrauterine pathologies, but their use usually requires an operation setting of the procedure and analgesia or anesthesia. The application of HTRs may reduce the time of the procedure and does not increase the complication rate as compared to resectoscopic myomectomy [22]. However, the HTR procedures require careful selection of patients.

An unquestionable advantage of hysteroscopy is the low risk of complications associated with the procedure. According to the available literature, the complication rate of hysteroscopy is about $1-2.7 \%$. The risk is mainly associated with the type of the procedure performed. It is suggested that the highest risk of complications (4.5\%) of hysteroscopy concerns the Asherman syndrome.

The early complications of hysteroscopy include bleeding, uterine perforation and infection. Uterine perforation is one of the most common complications of hysteroscopy $(0.12-3 \%)$ and is related to the uterine entry technique. The risk of bleeding is low $(0-0.16 \%)$, depends on the type of procedure and is the highest in adhesiolysis. Infections, especially endometritis (0.9\%) and urinary tract infections (0.6\%), are a rare complication of hysteroscopy.

Late complications are mainly associated with intrauterine adhesions. The incidence of adhesions is not well established and varies between $6.7 \%$ and $45.5 \%$. The risk of adhesion after hysteroscopy is strongly connected to the type of procedure performed [23].

The main challenge of office hysteroscopy is how to reduce the pain during the procedure. It is well known that pain is the main reason that patients do not always complete the procedure. The manipulation within the cervix, distention of the uterus and endometrial disruption or biopsy may cause unacceptable pain. It is essential to develop strategies, procedural and technical, which will be efficient in reducing the pain. Ogden et al. in their study found that the possibility of seeing the procedure may increase the patient's experience of pain. However, using mini-hysteroscopes, which are around $3.5 \mathrm{~mm}$, or flexible hysteroscopes, reduces the level of pain. Moreover, Mazzon et al. observed that using $\mathrm{CO}_{2}$ as a distension medium is associated with a lower pain level. The suggestions on efficacy of pharmacological pain control for office hysteroscopy remain inconsistent. There are a lot of studies comparing the effectiveness of different methods in reducing pain during hysteroscopy (e.g., lower intrauterine pressure, bladder-filling procedure, heated saline; electricity, music or hypnosis). However, there are evident discrepancies between the presented results [24-26].

The greatest strength of this study is the large number of patients enrolled and very comparable conditions of performing the procedures. All of them were performed at the same department, using the same devices, by a small group of very experienced surgeons. At the same time, there are certain limitations of the study. All data were analyzed retrospectively, and it was not always possible to clearly select the patients for a particular group according to the type of procedure performed. In certain cases, a patient had two or more procedures performed within the same hysteroscopic intervention. We believe that a prospective, carefully designed study may provide more accurate and reliable data on the appropriate selection of patients for office hysteroscopy.

\section{Conclusions}

To conclude, our analysis confirms that office 'see-and-treat' hysteroscopy without anesthesia is feasible in about $80 \%$ of cases. The main predictive factor of a successful office procedure is the multiparous status of the patient. For cervical dilatation procedures, also the postmenopausal status seems to be a good prognostic factor.

Our results can be easily applied in everyday clinical practice and can help in the proper qualification of patients.

The best candidates for office hysteroscopy are: - all patients who required only a diagnostic procedure,

- all multiparous women, regardless of the type of procedure required,

- postmenopausal women who required a cervical dilatation procedure.

We should avoid office minihysteroscopy in the case of large endometrial resection procedures, as 
well as in patients with large intrauterine pathologies (myomas or polyps).

Future studies are needed to assess the implications of an unsuccessful office hysteroscopy in the patient's history for the next procedures. Also, the use of HTRs and the need for analgesia requires further studies.

\section{Acknowledgments}

This work was supported by Statutory Grant no. 433 of the Military Institute of Medicine, Warsaw, Poland.

\section{Conflict of interest}

The authors declare no conflict of interest.

\section{References}

1. Mairos J, Di Martino, P. Office hysteroscopy. An operative gold standard technique and an important contribution to patient safety. Gynecol Surg 2016; 13: 111-4.

2. Kamiński P, Ziółkowska K, Szymusik I, Gajewska M. The use of hysteroscopy in diagnosing and treatment of the septate uterus: author's experience and literature review. Videosurgery Miniinv 2006; 1: 101-9.

3. Hassan A, Haggag $\mathrm{H}$. Role of oral tramadol $50 \mathrm{mg}$ in reducing pain associated with outpatient hysteroscopy: a randomised double-blind placebo-controlled trial. Aust N Z I Obstet Gynaecol 2016; 56: 102-6.

4. Cicinelli E, Didonna T, Schonauer LM, et al. Paracervical anesthesia for hysteroscopy and endometrial biopsy in postmenopausal women. A randomized, double-blind, placebo-controlled study. J Reprod Med 1998; 43: 1014-8.

5. Giorda G, Scarabelli C, Franceschi S, Campagnutta E. Feasibility and pain control in outpatient hysteroscopy in post-menopausal women: a randomized trial. Acta Obstet Gynecol Scand 2000; 79: 593-7.

6. Bettocchi S, Selvaggi L. A vaginoscopic approach to reduce the pain of office hysteroscopy. J Am Assoc Gynecol Laparosc 1997; 4: $255-8$.

7. Garbin O, Kutnahorsky R, Gollner JL, Vayssiere C. Vaginoscopic versus conventional approaches to outpatient diagnostic hysteroscopy: a two-centre randomized prospective study. Hum Reprod 2006; 21: 2996-3000.

8. Cooper NA, Smith P, Khan KS, Clark TJ. Vaginoscopic approach to outpatient hysteroscopy: a systematic review of the effect on pain. BJOG 2010; 117: 532-9.

9. Sagiv R, Sadan O, Boaz M, et al. A new approach to office hys teroscopy compared with traditional hysteroscopy. Obstet Gynecol 2006; 108: 387-95.

10. Moawad NS, Santamaria E, Johnson M, Shuster J. Cost-effectiveness of office hysteroscopy for abnormal uterine bleeding. JSLS 2014; 18: e2014.00393.
11. Bettocchi S, Selvaggi L. A vaginoscopic approach to reduce the pain of office hysteroscopy. J Am Assoc Gynecol Laparosc 1997; 4: 255-8.

12. Cooper NA, Smith P, Khan KS, Clark TJ. Vaginoscopic approach to outpatient hysteroscopy: a systematic review of the effect on pain. BJOG 2010; 117: 532-9.

13. Rodrigues M, DiMartino P, Mairos J. Excision of intracavitary masses in office hysteroscopy - what are the limits? Acta Obstet Ginecol Port 2014; 8: 252-6.

14. Paulo AA, Solheiro MH, Paulo CO, Afreixo VM. What proportion of women refers moderate to severe pain during office hysteroscopy with a mini-hysteroscope? A systematic review and meta-analysis. Arch Gynecol Obstet 2016; 293: 37-46.

15. Van Dongen, H, De Kroon CD, Van Den Tillaart SA, et al. A randomised comparison of vaginoscopic office hysteroscopy and saline infusion sonography: a patient compliance study. BJOG 2008; 115: 1232-7.

16. de Kroon CD, de Bock GH, Dieben SW, Jansen FW. Saline contrast hysterosonography in abnormal uterine bleeding: a systematic review and meta-analysis. BJOG 2003; 110: 938-47.

17. Capmas P, Pourcelot AG, Giral E, et al. Office hysteroscopy: a report of 2402 cases. J Gynecol Obstet Biol Reprod 2016; 45: 445-50.

18. Campo R, Molinas CR, Rombauts L, et al. Prospective multicentre randomized controlled trial to evaluate factors influencing the success rate of office diagnostic hysteroscopy. Hum Reprod 2005; 20: 258-63.

19. Török P, Major T. Evaluating the level of pain during office hysteroscopy according to menopausal status, parity, and size of instrument. Arch Gynecol Obstet 2013; 287: 985-8.

20. Gambadauro P, Martínez-Maestre MA, Torrejón R. When is seeand-treat hysteroscopic polypectomy successful? Eur J Obstet Gynecol Reprod Biol 2014; 178: 70-3.

21. Laganà AS, Vitale SG, Muscia V, et al. Endometrial preparation with Dienogest before hysteroscopic surgery: a systematic review. Arch Gynecol Obstet 2017; 295: 661-7.

22. Vitale SG, Sapia F, Rapisarda AMC, et al. Hysteroscopic morcellation of submucous myomas: a systematic review. Biomed Res Int 2017; 2017: 6848250.

23. Aas-Eng MK, Langebrekke A, Hudelist G. Complications in operative hysteroscopy - is prevention possible? Acta Obstet Gynecol Scand 2017; 96: 1399-403.

24. Ogden J, Heinrich M, Potter C, et al. The impact of viewing a hysteroscopy on a screen on the patient's experience: a randomised trial. BJOG 2009; 116: 286-93.

25. Mazzon I, Favilli A, Grasso M, et al. Pain in diagnostic hysteroscopy: a multivariate analysis after a randomized, controlled trial. Fertil Steril 2014; 102: 1398-403.

26. Amer-Cuenca JJ, Marín-Buck A, Vitale SG. Non-pharmacological pain control in outpatient hysteroscopies. Minim Invasive Ther Allied Technol 2019 DOI: 10.1080/13645706.2019.1576054.

Received: 8.05.2019, accepted: 23.08.2019. 